\title{
Mortality of Nymphal Instars of Anthocoris nemoralis (Heteroptera: Anthocoridae) Exposed to different Insecticides under Laboratory Conditions
}

\author{
Baboo Ali (Corresponding author) \\ Canakkale Onsekiz Mart University, Faculty of Agriculture, \\ Department of Field Crops, Terzioglu Campus, 17100, Canakkale, Turkey \\ E-mail: babooali@comu.edu.tr \\ Avni Ugur \\ Ankara University, Faculty of Agriculture, Department of Plant Protection, \\ 06110, Diskapi, Ankara, Turkey \\ E-mail: ugur@agri.ankara.edu.tr
}

\begin{abstract}
Pesticides not only minimize the population of certain notorious insect pests of our important fruit, vegetables and crops, but they also contaminate our soil, water as well as the environment. Intensive and unconscious application of pesticides also cause economic damage to our important plants and such situation is called as phytotoxicity. Different species of parasitoids and predatory insects are naturally found in ecosystem to fight against the population of harmful insects of our agricultural products. But unfortunately, the population of natural enemies are being affected because of the usage of pesticides. Anthocoris nemoralis (F.) is one of the polyphagous predatory insects which helps to keep the population of certain harmful insect pests under economic injury level to our important plants. The main objective of this research work is to investigate the side-effects of commonly used insecticides in the chemical control of insect pests of fruit orchards where this predatory bug is naturally found. According to the obtained results from this research study, the highest mortality rate $(96.66 \%)$ was found in chlorpyrifos ethyl and spinetoram treated $3^{\text {rd }}$ nymphal instars of the predatory bug, but the lowest mortality rate $(76.66 \%)$ has been recorded in the individuals of same nymphal instars treated with diflubenzuron insecticide after 72 hours. In case of the $5^{\text {th }}$ nymphal instars of the predatory bug, the mortality rate didn't show a significant difference with relation to different insecticides application. It is concluded that the A. nemoralis has different level of susceptibility to different active ingredients during both nymphal stages. Thus, diflubenzuron and spinetoram are suggested to be used in the integrated pest management program of the insect pests of fruit orchards along with the presence of the $3^{\text {rd }}$ and $5^{\text {th }}$ nymphal instars of the predatory bug, respectively because these two active ingredients cause low mortality to this beneficial insect.
\end{abstract}

Keywords: Anthocoris nemoralis, Biocontrol, Insecticide, Mortality, Nymphal instar, Predatory bug

DOI: $10.7176 /$ JSTR/6-09-10

\section{Introduction}

In Turkey, there are over 550 different kinds of harmful organisms which cause economic losses to agricultural productions (Birisik, 2013). Pesticides are extremely effective, easy-to-apply, generally economical and powerful tools used in the chemical control of many notorious insect pests. However, the indiscriminate, inadequate and inappropriate application of pesticides cause serious problems such as improving resistance in different species of insect pests, revival of target species, epidemic of secondary insect pests, destruction of beneficial and farmer-friendly insect species, as well as health hazards and environmental pollution. For all these reasons, long-term studies are required to evaluate suitable and environment-friendly products (pesticides) in order to be used in plant protection strategy.

106 | P a g e

www.iiste.org 
Annual pesticide use amount in the world is 3 million/ton/year and its monetary value is worth 30 million euro (Delen, 2008). In our country, this rate exceeds upto 33 thousand/ton/year and the approximate market value is worth 230-250 million dollars (Turabi, 2007). In Turkey, it has negative effects on health, environment, ecology and economy because of the intensive use of pesticides in viticulture and pomology (fruit farming) sectors. One of the most obvious examples in this regard is in pear fruit production. Currently, the number of pear varieties grown in Turkey are reported to be over 600 different varieties (Kaska et al., 2005). The annual world pear fruit production is slightly above to 17 million tons, while in Turkey, the total number of pear fruit trees have been reported as 12-13 million, and the annual production of pear fruit has been recorded as 340-370 thousand/ton/year. Many important plant protection problems are being faced in pear fruit (Prunus spp.) production, in case of our country, the main insect pest of pear orchards is the Cacopsylla pyri (Hemiptera: Psyllidae). The nymphal and adult stages of this harmful insect cause damage by feeding on the green leaves and shoots of pear trees. The growth of pear trees stops and the fruit deformities can also occur along with leaf and fruit dumping in cases where the population of Cacopsylla pyri is dense. In the recent days, in our country, this insect pest has gained considerable resistance to pesticides due to the intensive and unconscious application of pesticides in the control of $C$. pyri. There has been an increase in pesticides consumption due to this durability. As a result, alternative methods (i.e., biological control, biotechnological control, cultural control, application of biopesticides, etc.) of insect pests control should be introduced against $C$. pyri in pear orchards. Among these methods of insect pests' control, priority should be given to biological control method of insect pests. This method of control not only keeps the population of certain harmful insect pests under pressure, but it also increases the sustainability of agroecosystems (Rusch et al., 2010). Biological control is the manipulation of one or more kinds of beneficial entities, usually known as natural enemies, to reduce the population fluctuations of another kinds of harmful organisms, called the pests (Mahr et al., 2001).

At the beginning of biological control methods against pear psylla, the natural enemy named Anthocoris nemoralis (F.) (Heteroptera: Anthocoridae), the most important predatory bug that keeps the population of Cacopsylla pyri under pressure in pear orchards as well as under field conditions. In present time, in many developed countries, A. nemoralis has different commercial applications to solve the problem of $C$. pyri in pear orchards. However, there is no commercial production of this beneficial predatory bug in our country, whereas, this farmer-environment-friendly insect is naturally found in agroecosystem. Certain taxonomic studies have been conducted on this predatory insect in our country. In addition to this, very important research works have been done on rearing, predator-prey interactions and different field releasing techniques of $A$. nemoralis in our country (Yanik and Ugur, 2004; Yanik and Ugur, 2005; Yanik, 2006; Yanik, 2011). But in case of Turkey, there was no any research work found regarding to the side effects of pesticides on A. nemoralis which will formulate the basis for the evaluation of the side-effects of different pesticides application on this predatory bug under natural field conditions.

Our research study has been carried out aim to determine the mortality rates of the predatory bug, Anthocoris nemoralis (F.) (Heteroptera: Anthocoridae) used as biocontrol agent in fruit orchards when its different nymphal instars were exposed to four different insecticides for the periods of 1,2 and 3 days under sprayed conditions. Therefore, with the help of this study, contributions will be made to determining the integrated pest management programs used primarily in biological control of pear psylla in particular, in other notorious insect pests of fruit orchards in general, in our country.

\section{Materials and Methods}

In this study, the predatory bug Anthocoris nemoralis (F.) (Heteroptera: Anthocoridae) and the eggs of Ephestia kuehniella Zeller (Lepidoptera: Pyralidae) have been used as living materials. Four different insecticides with the active ingredients of chlorpyrifos ethyl, spirotetramat, spinetoram and diflubenzuron were used aim to determine the effects of these insecticides on the survival of two different nymphal stages ( $3^{\text {rd }}$ and $5^{\text {th }}$ instars) of the predatory bug in this research work. The adult individuals of the predatory bug were collected from the wild, neglected and unsprayed pear orchards located in the Cubuk District of Ankara Province of Turkey. After that, the collected adult individuals of the predatory bug have been brought to the mass rearing laboratory of the Ankara University in the Faculty of Agriculture, Department of Plant Protection and they were placed in the incubatory room under the rearing conditions of $25 \pm 1{ }^{\circ} \mathrm{C}$ temperature, $70 \pm 10 \%$ relative humidity, $16: 8$ (L:D) hours of photoperiods and 2500 lux of light intensity. The individuals of $A$. nemoralis have been fed by offering them the fresh eggs of Ephestia kuehniella on daily basis. The side effects of four different insecticides

107 | P a g e

www.iiste.org 
(Table 1) have been investigated when an ample amount of the nymphal instars (particularly $3^{\text {rd }}$ and $5^{\text {th }}$ instars) of the predatory bug were obtained from its mass reared population.

Table 1. The properties of insecticides which side effects were examined on the nymphal instars of

\begin{tabular}{llclc}
\multicolumn{5}{c}{ Anthocoris nemoralis } \\
\hline Trade names & Active ingredients & \multicolumn{1}{c}{ Applied doses } & Name of company & Formulation \\
\hline Dursban 4 & Chlorpyrifos ethyl & $100 \mathrm{ml} / 100 \mathrm{lt}$ water & Dow AgroSciences & EC \\
Movento 100 & Spirotetramat & $100 \mathrm{ml} / 100 \mathrm{lt}$ water & Bayer CropScience & SC \\
Delegate 250 & Spinetoram & $40 \mathrm{ml} / 100 \mathrm{lt}$ water & Dow AgroSciences & WG \\
Dimilin 48 & Diflubenzuron & $25 \mathrm{ml} / 100 \mathrm{lt}$ water & Certis \& Chemtura & SC
\end{tabular}

The insecticide concentrations, have been prepared in this research work, were sprayed to each glass petri dish using $2 \mathrm{ml}$ spraying method with the help of a spraying tower (Potter, 1952). Later, the treated glass petri dishes were kept to dry for 30-45 minutes, then the newly emerged (0-24 hours) $3^{\text {rd }}$ and $5^{\text {th }}$ nymphal instars of $A$. nemoralis were collected from the stock culture (Cubuk District Culture) and a total of 10 individuals from each nymphal instar were transferred to each insecticide treated petri dishes. Freshly laid (0-24 hours) eggs of $E$. kuehniella, which were kept under $-4{ }^{\circ} \mathrm{C}$ of temperature for 72 hours by adhering on $1 \times 1 \mathrm{~cm}$ black cardboard strips with distilled water before presented as food to the $3^{\text {rd }}$ and $5^{\text {th }}$ nymphal instars of $A$. nemoralis during the whole research work. This prepared food (eggs of E. kuehniella) was given to the individuals of both nymphal stages of the predatory bug after every 24 hours. The treated experimental trials were carried out with 6 replications for each insecticides and a total of 10 individuals have been placed into each replication. All surviving and dead individuals have been counted regularly after 24,48 and 72 hours of insecticide application in all treatments, including the control treatment. A smooth small brush was used for the confirmation whether living or dead condition of the nymphal stages of the predatory bug after every 24 hours after insecticide application to insect containing petri dishes. Experimental trials have been conducted separately each for $3^{\text {rd }}$ and $5^{\text {th }}$ nymphal instars of $A$. nemoralis. The obtained results from the experiment have been evaluated based on the total number of dead individuals (mortality rate percentage) in each treatment. The percentage effects of four different insecticides were calculated by Abbott's formula [Population\% $=($ pretreatment population in treatment - posttreatment population in treatment $\div$ population without insecticide application) $\times$ 100] (Abbott, 1925; Karman, 1971). The obtained results have been evaluated according to the standards adopted by the IOBC working group for the effects of insecticides on natural enemies under laboratory conditions, and have been classified according to the toxicity effects of pesticides in Table 2 (Boller et al., 2006). The data obtained from this research work were subjected to variance analysis in the 'Minitab 15' package program. The differences between the sideeffect of different insecticides on different nymphal instars of the predatory bug were evaluated within the standard error of $\mathrm{P} \leq 0.05$ using the "Tukey Test" included in the "MSTAT" package program.

Table 2. Classification of the side-effect of insecticides established IOBC ${ }^{*}$ criteria for laboratory tests

\begin{tabular}{ccl}
\hline Class value & Toxic effect $(\%)$ & Toxicity level \\
\hline $\mathrm{N}$ & $<30$ & Harmless or slightly harmful \\
$\mathrm{M}$ & $30-79$ & Moderately harmful \\
$\mathrm{T}$ & $>80$ & Harmful \\
\hline
\end{tabular}

\section{Results}

\subsection{Mortality rate of $3^{\text {rd }}$ nymphal instars of Anthocoris nemoralis}

It has been observed that the residual effect of four different insecticides on the $3^{\text {rd }}$ nymphal instar of $A$. nemoralis shown an increase with the passage of time after insecticide applications $\left(\mathrm{df}=2, \mathrm{~F}_{\text {Dur }}=63.76\right.$, $\left.\mathrm{P}=0.000 ; \mathrm{df}=2, \mathrm{~F}_{\mathrm{Mov}}=12.76, \mathrm{P}=0.007 ; \mathrm{df}=2, \mathrm{~F}_{\mathrm{Dim}}=5.30, \mathrm{P}=0.047 ; \mathrm{df}=2, \mathrm{~F}_{\text {Del }}=45.48, \mathrm{P}=0.000\right)$. The difference between the toxic/residual effects of insecticides was found statistically significant at the $24^{\text {th }}, 48^{\text {th }}$ and $72^{\text {nd }}$ hours $\left(\mathrm{df}=2, \mathrm{~F}_{24}=1.45, \mathrm{P}=0.298 ; \mathrm{df}=2, \mathrm{~F}_{48}=0.83, \mathrm{P}=0.513 ; \mathrm{df}=2, \mathrm{~F}_{72}=4.41, \mathrm{P}=0.041\right)$. It has been concluded that all of the four different insecticides are placed in the moderately harmful (M) class of IOBC criteria when their side-effect was calculated by using Abbott percentage formula given in Table 3.

108 | P a g e

www.iiste.org 
Table 3. Mortality rates of $3^{\text {rd }}$ nymphal instars of Anthocoris nemoralis exposed to different insecticides for different periods of time

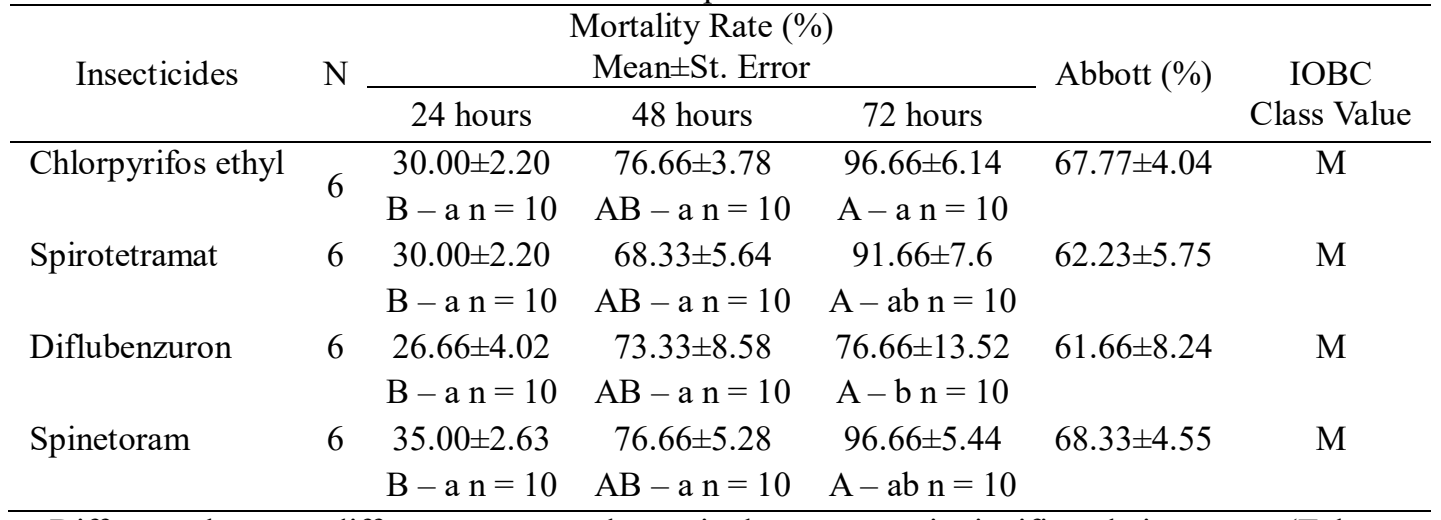

Difference between different uppercase letters in the same row is significantly important (Tukey, $\mathrm{P} \leq 0.05)$, Difference between different lowercase letters in the same column is significantly important (Tukey, $\mathrm{P} \leq 0.05$ ).

\subsection{Mortality rate of $5^{\text {th }}$ nymphal instars of Anthocoris nemoralis}

It has been shown that the residual effect of four different insecticides increased on the $5^{\text {th }}$ nymphal instars of the predatory bug with the passage of time $\left(\mathrm{df}=2, \mathrm{~F}_{\mathrm{Dur}}=51.59, \mathrm{P}=0.000 ; \mathrm{df}=2, \mathrm{~F}_{\mathrm{Mov}}=26.85\right.$, $\left.\mathrm{P}=0.001 ; \mathrm{df}=2, \mathrm{~F}_{\mathrm{Dim}}=29.75, \mathrm{P}=0.001 ; \mathrm{df}=2, \mathrm{~F}_{\mathrm{Del}}=21.87, \mathrm{P}=0.002\right)$. Difference between the residual effects of insecticides was found significantly important at $24^{\text {th }}, 48^{\text {th }}$ and $72^{\text {nd }}$ hours $\left(\mathrm{df}=2, \mathrm{~F}_{24}=9.65\right.$, $\left.\mathrm{P}=0.005 ; \mathrm{df}=2, \mathrm{~F}_{48}=11.64, \mathrm{P}=0.003 ; \mathrm{df}=2, \mathrm{~F}_{72}=14.08, \mathrm{P}=0.001\right)$. It has been concluded that all of the four different insecticides are took place in the moderately harmful (M) class of IOBC criteria when their side-effect was calculated by using Abbott percentage formula shown in Table 4.

Table 4. Mortality rates of $5^{\text {th }}$ nymphal instars of Anthocoris nemoralis exposed to different insecticides for different periods of time

\begin{tabular}{|c|c|c|c|c|c|c|}
\hline \multirow{3}{*}{ Insecticides } & \multicolumn{4}{|c|}{ Mortality Rate (\%) } & \multirow{3}{*}{ Abbott (\%) } & \multirow{3}{*}{$\begin{array}{c}\text { IOBC } \\
\text { Class Value }\end{array}$} \\
\hline & \multirow[b]{2}{*}{$\mathrm{N}$} & \multicolumn{3}{|c|}{ Mean \pm St. Error } & & \\
\hline & & 24 hours & 48 hours & 72 hours & & \\
\hline \multirow[t]{2}{*}{ Chlorpyrifos ethyl } & 6 & $10.00 \pm 2.99$ & $46.66 \pm 6.09$ & $81.66 \pm 7.02$ & $46.11 \pm 5.36$ & $\mathrm{M}$ \\
\hline & & $C-a n=10$ & $B-a n=10$ & $A-a n=10$ & & \\
\hline \multirow[t]{2}{*}{ Spirotetramat } & 6 & $10.00 \pm 2.60$ & $45.00 \pm 4.49$ & $85.00 \pm 6.47$ & $46.66 \pm 4.52$ & M \\
\hline & & $C-b n=10$ & $B-b n=10$ & $A-b n=10$ & & \\
\hline \multirow[t]{2}{*}{ Diflubenzuron } & 6 & $16.66 \pm 2.45$ & $53.33 \pm 3.39$ & $83.33 \pm 3.37$ & $51.11 \pm 3.07$ & M \\
\hline & & $C-b n=10$ & $B-b n=10$ & $A-b n=10$ & & \\
\hline \multirow[t]{2}{*}{ Spinetoram } & 6 & $11.66 \pm 2.77$ & $45.00 \pm 5.88$ & $80.00 \pm 7.60$ & $45.55 \pm 5.42$ & M \\
\hline & & $B-a b n=10$ & $B-b n=10$ & $A-b n=10$ & & \\
\hline
\end{tabular}

Difference between different uppercase letters in the same row is significantly important (Tukey, $\mathrm{P} \leq 0.05)$, Difference between different lowercase letters in the same column is significantly important (Tukey, $\mathrm{P} \leq 0.05$ ).

\section{Discussion}

According to the overall results of this research work, it has been observed that the spinetoram and chlorpyrifos ethyl active ingredients caused the highest residual effect on the $3^{\text {rd }}$ nymphal instar of the predatory bug with $96.66 \%$ mortality rates. On the other hand, it was determined that spirotetramat and diflubenzuron were effective with the highest mortality rates of $85 \%$ and $83.33 \%$, respectively on the $5^{\text {th }}$ nymphal instars of $A$. nemoralis. According to the overall results, it can be said that the $3^{\text {rd }}$ nymphal instars of the predatory bug are more sensitive and affected by the application of these four insecticides than that of the $5^{\text {th }}$ nymphal stages of $A$. nemoralis. In addition, it has also been determined that the mortality rates of the both nymphal stages $\left(3^{\text {rd }}\right.$ and $5^{\text {th }}$ nymphal instars) are gradually increased during 24, 48 and 72 hours in terms of four different tested insecticides. Indeed, in another study, different 
insecticides (Azadirachtin-neem, tropane-datura and imidacloprid) have been applied in the chemical control of Diaphorina citri (Hemiptera: Psyllidae), including spinetoram and spirotetramat, and the researchers of this study also determined the effects of insecticides on some predatory insect species. As the result, researchers have reported that the spinetoram and other applied insecticides do not cause a decrease in the population of predatory insect species such as Adalia bipunctata, Aneglei scardoni, Cheilomenes sexmaculata and Coccinella septempunctata (Khan et al., 2014).

In our study, the mortality rate occurred due to the application of spinetoram active ingredient on the $3^{\text {rd }}$ and $5^{\text {th }}$ nymphal instars of $A$. nemoralis has been recorded above $80 \%$. Malagnoux et al. (2015) stated that the Forficula auricularia is an effective predatory insect in apple orchards, and they have reported a reduction of $98 \%$ and $62 \%$ in the predation activities of the nymphal stages of this predatory insect (F. auricularia) when remained under the influence of chlorpyrifos ethyl and spinosad, respectively. However, Miret and Garcia-Mari (2001) indicated that the chlorpyrifos ethyl is slightly/less harmful $(\mathrm{N})$, pyriproxyfen is moderately harmful $(\mathrm{M})$ and mineral oil is harmless $(\mathrm{N})$ to the larvae of Cryptoleamus montrouzieri during their study conducted regarding the side-effects of pesticides on selected natural enemies. However, in our study, the side-effect of chlorpyrifos ethyl on both of the nymphal instars $\left(3^{\text {rd }}\right.$ and $5^{\text {th }}$ instars) of $A$. nemoralis was found to be moderately harmful $(\mathrm{M})$. In a research study, conducted by Ruiz-Sánchez et al. (2010), they investigated the side-effects of diflubenzuron on the immature stages of the predatory insect Harmonia axyridis Pallas (Coleoptera: Coccinellidae). Ruiz-Sánchez et al. (2010) reported that the diflubenzuron, which takes place in IGR group, caused high mortality rates and enhanced the developmental period of the predator insect especially, in $1^{\text {st }}$ and $2^{\text {nd }}$ larval stages. Similar side-effect has been observed on the $3^{\text {rd }}$ and $5^{\text {th }}$ nymphal instars of $A$. nemoralis during our study. The highest mortality rate $(96.66 \%)$ was found in spinetoram treated petri dishes after 72 hours in the $3^{\text {rd }}$ nymphal instars of the predatory bug, but it has been recorded as $85 \%$ after the same time period in spirotetramat treated petri dishes containing the $5^{\text {th }}$ nymphal instars of the bug. It was indicated that the $A$. nemoralis had different level of sensitivity to different active ingredients in both nymphal stages.

Lefebvre et al. (2012) stated that the spinetoram and spirotetramat caused $100 \%$ and $40.2 \%$ mortality rates in adult stages of the predatory mite Neoseiulus fallacis (Acari: Phytoseiidae), respectively. In another study, it has been reported that the high dose of spirotetramat 150 OD causes $28.88 \%$ of mortality to the predatory insect Chrysoperla zastrowisillemi (Esberson Peterson) (Neuroptera: Chrysopidae), and this active ingredient is suggested can be used in the integrated pest management program due to its slightly harmful/harmless $(\mathrm{N})$ effect on the population of natural enemies used as biocontrol agents (Amala et al., 2015).

\section{Conclusion}

According to the overall results of this research work, it has been observed that the highest mortality rate of the $3^{\text {rd }}$ nymphal instar of $A$. nemoralis recorded in the treatments applied with spinetoram, while in case of the $5^{\text {th }}$ nymphal instar of the predatory bug, the highest mortality rate was noted in diflubenzuron treated individuals. The lowest mortality rate has been observed in the $3^{\text {rd }}$ nymphal stages of the bug when treated with diflubenzuron and in case of the $5^{\text {th }}$ nymphal instar, the lowest mortality rate was recorded in the experimental trials treated with movento insecticide. In both nymphal instars of the predatory bug, the variation in mortality rates was similar according to the staying duration of nymphal stages in insecticides. The lowest mortality rates (12.08-30.42\%) were determined on the first day, while the highest mortality rates $(90.41-82.50 \%)$ of the nymphal stages of $A$. nemoralis have been reported at the end of the third day after the conduction of the experimental trials. The average mortality rate in the $3^{\text {rd }}$ nymphal instar of the predatory bug was recorded as $64.86 \%$, while it was determined as $47.84 \%$ in the $5^{\text {th }}$ nymphal instar according to different insecticides and their application period of times.

In this study, it has been concluded that the most suitable insecticide that can be used in the chemical control of insect pests along with the integrated pest management program of fruit orchards is spirotetramat, which is least harmful $(30-79 \%)$ insecticide to the nymphal instars of A. nemoralis, particularly, to the $5^{\text {th }}$ nymphal instars of the predatory bug used as biocontrol agent in fruit orchards in the control of C. pyri.

Note: This research paper is a part of the $\mathrm{PhD}$ dissertation of Dr. Baboo Ali. 


\section{References}

Abbott, W.S. (1925). A method of computing the effectiveness of an insecticide. Journal of Economic Entomology, 18, 265-267.

Amala, U., Chinniah, C., Sawant, I.S., Muthukrishnan, N., \& Muthiah, C. (2015). Safety evaluation of spirotetramat 150 OD against predator Chrysoperla zastrowisillemi (Esberson Peterson) (Neuroptera: Chrysopidae) under laboratory conditions. J. Biopest., 8(1): 52-55.

Birisik, N. (2013). Biotechnological control from theory to practice. Turkish Ministry of Food, Agriculture and Livestock. General Directorate of Food and Control, Ankara, 189 pp.

Boller, E.F., Vogt, H., Ternes, P., \& Malavolta, C. (2006). Working document on selectivity of pesticides (2005). Internal newsletter issued by the publication commission for the IOBC/WPRS Council and Executive Committee, Issue No: 40.

Delen, N. (2008). Fungicides. Nobel Publications, Izmir-Turkey.

Karman, M. (1971). General information on plant protection researches, the establishment of experiments and assessment principles. Turkish Ministry of Agriculture, Text Book Series, General Directorate of Plant Protection Central Research Institute, Regional Plant Protection Research Centre, Bornova/Izmir, 279 pp.

Kaska, N., Guleryuz, M., Kaplankiran, M., Kafkas, S., Ercisli, S., Esitken, A., Aslantas, R., \& Akcay, E. (2005). Targets of fruit production in Turkey. $6^{\text {th }}$ Technical Congress of Turkish Agricultural Engineering, 3-7 October 2005, Ankara, 01, 519-549 pp.

Khan, A.A., Afzal, M., Qureshi, J.A., Khan, A.M., \& Raza, A.M. (2014). Botanicals, selective insecticides, and predators to control Diaphorina citri (Hemiptera: Liviidae) in citrus orchards. Insect Science, 21: 717-726.

Lefebvre, M., Bostanian, N.J., Mauffette, Y., Racette, G., Thistlewood, H.A., \& Hardman, J.M. (2012). Laboratory-based toxicological assessments of new insecticides on mortality and fecundity of Neoseiulus fallacis (Acari: Phytoseiidae). Journal of Economic Entomology, 105(3): 866-871.

Mahr, S.E.R., Cloyd, R.A., Mahr, D.L., \& Sadof, C.S. (2001). Biological control of insects and other pests of greenhouse crops. North Central Regional Publication 581. University of Wisconsin-Extension, Cooperative Extension, 98 pp.

Malagnoux, L., Marliac, G., Simon, S., Rault, M., \& Capowiez, Y. (2015). Management strategies in apple orchards influence earwig community. Chemosphere, 124, 156-162 pp.

Miret, J-A.J., \& Garcia-Mari, F. (2001). Side-effects of pesticides on selected natural enemies occurring in citrus in Spain. Pesticides and Beneficial Organisms, IOBC/WPRS Bulletin, 24(4): $103-112$

Potter, C. (1952). An improved laboratory apparatus for applying direct sprays and surface films with data on the electrostatic charge on atomized spray fluids. Annals of Applied Biology, 39, 1$28 \mathrm{pp}$.

Ruiz-Sánchez, E., Caamal-Eb, L., Cristóbal-Alejo, J., Munguía-Rosales, R., \& Pérez-Gutiérrez, A. (2010). Survivorship and development of immature Harmonia axyridis Pallas (Coleoptera: Coccinellidae) exposed to diflubenzuron. Agrociencia, 44(3): 373-379. 
Rusch, A., Morison, M.A., Sarthou, J.P., \& Estrade, J.R. (2010). Biological control of insect pests in agroecosystems: Effects of crop management, farming systems, and seminatural habitats at the landscape scale: A review. Advances in Agronomy, 109, 219-248 pp.

Turabi, M.S. (2007). Licensing of plant protection products. Pesticides Congress and Exhibition Papers, 25- 26 October 2007, Ankara, 50-61 pp.

Yanik, E. (2006). Determination of the effects of different preys on the reproductive biology of Anthocoris nemoralis (F.) (Heteroptera: Anthocoridae). Turkish Journal of Entomology, 30(1): 57-65.

Yanik, E. (2011). The effects of different temperatures and relative humidity on the nymphal development, mortality and prey consumption of Anthocoris nemoralis (F.) (Heteroptera: Anthocoridae). Selcuk Journal of Agriculture and Food Sciences, 25(4): 21-26.

Yanik, E., \& Ugur, A. (2004). Consumption of Cacopsylla pyri (L.) (Homoptera: Psyllidae) and Ephestia kuehniella Zell. (Lepidoptera: Pyralidae) eggs by predator Anthocoris nemoralis (F.) (Heteroptera: Anthocoridae) under laboratory and natural conditions. Plant Protection Bulletin, 44(1-4): 47-67.

Yanik, E., \& Ugur, A. (2005). Investigations on the fecundity of predator Anthocoris nemoralis (F.) (Heteroptera: Anthocoridae) under laboratory and natural conditions. Turkish Journal of Entomology, 29(2): 111-124. 